\title{
APUNTES PARA LA CONTEXTUALIZACIÓN DE LA CREACIÓN LITERARIA DESDE EL MARGEN: EL NUEVO NEOBARROCO DIGITAL
}

\author{
NOTES TOWARDS THE CONTEXTUALIZATION OF LITERARY CREATION \\ FROM THE MARGIN: THE NEW DIGITAL NEO-BAROQUE
}

Raisa Gorgojo Iglesias

Universidad de Oviedo

\section{Resumen:}

La democratización tecnológica abre la puerta a un análisis con perspectiva feminista, dado que las tradicionales trabas al acceso a la creación literaria parecen difuminarse. Esta es una propuesta para contextualizar los nuevos textos surgidos al margen de lo canónico y con soportes virtuales que pretende imbricar las teorías sobre Hipermodernismo y Neobarroco, que estudian el horror vacui de la narrativa actual, pero que no dialogan entre sí.

\section{Palabras clave:}

neobarroco, hipermodernismo, feminista, narrativa transmedia.

crítica

\section{Abstract:}

Technological democratization opens the door to an analysis with a feminist perspective, since the traditional obstacles to access literary creation tools seem to be disappearing. This is a proposal to contextualize the new texts that emerged outside the canon and within virtual environments. The present work intends to overlap the theories about Hypermodernism and Neo-Baroque: both of them study the horror vacui of the current narrative), but they do not dialogue with each other.

\section{KEYWORDS:} neo-baroque, hipermodernism, feminist critical analysis, transmedia narrative. 


\section{INTRODUCCIÓN: LA NECESIDAD DE FOTOGRAFIAR LAS NUEVAS ESCRITURAS MARGINALES}

Este trabajo propone un estudio general del Neobarroco como una superestructura cultural que engloba una variada tipología de expresiones artísticas y literarias contemporáneas, un nuevo marco teórico producto de un hibridismo nacido en un tejido cultural complejo e interconectado gracias al crecimiento exponencial de las redes sociales. En ese sentido, pretende servir como marco teórico a un futuro análisis sobre cómo las autoras se mueven en un espacio sin límites, el virtual, cuestionando si se trata de herramientas que permiten configurar discursos desde la diversidad o si en ese nuevo espacio se reproduce la dicotomía discurso canónico-discurso periférico. Se trata a todas luces de un trabajo en proceso, de una propuesta para contextualizar estos nuevos textos nacidos al margen de lo canónico. Si bien es cierto que existen estudios de la hipermodernidad, de las nuevas narrativas (transmedia ${ }^{1}$ o multimedia) no dialogan con las teorías sobre el Neobarroco y el horror vacui del storytelling contemporáneo a pesar de sus marcadas interseccionalidades.

A la luz de las teorías de Ardener (2005) sobre el Muted Group que examinan cómo los grupos sin prestigio, en cuanto oprimidos (paradigma aplicable a cuestiones de género, raza y clase), no cuentan con las herramientas necesarias para elaborar un discurso propio, modificando por tanto no solo la recepción y la subalternidad de sus textos sino también la construcción de los mismos, cabe preguntarse entonces qué sucede con las narraciones nacidas en y para las redes sociales, a la luz asimismo de una democratización tecnológica que a priori parece permitir la difusión de voces y experiencias periféricas.

En ese aspecto existen hoy en día creadores y creadoras que narran no solo sus propias vivencias, sino que también contribuyen a una nueva metanarrativa: es decir, diseccionan los textos existentes y expanden universos cerrados, como en el caso de la fanfiction. Estos nuevos textos equilibran el uso de la palabra con la imagen y el hipervínculo, pudiendo hablarse por tanto de una nueva intertextualidad consolidada que forma parte de nuestra cotidianidad desde la multiplicidad de lenguajes creados en las redes sociales (por ejemplo, en una misma red social como Instagram tenemos texto, imagen estática e imágenes en movimiento). En ese sentido, podemos considerarnos "webactors" (Tranche 2016), es decir, generadores de contenido: para ello, además, no es necesaria una intencionalidad narrativa específica, pues como webactors podemos participar de modo directo (reposteando con comentario, participando activamente en nuevas formas de literatura, bionarrándonos en stories) e indirecto (likes, tiempo de conexión en un post). Cualquier movimiento condiciona la forma en que se genera contenido, por parte de individuos y empresas: se trata de un mecanismo de estímulo- 
recompensa, es decir, el contenido que más interacción genere será aquel que más se produzca para alcanzar la exposición deseada.

El objetivo de este trabajo, en definitiva, es ofrecer unas bases sobre las que explorar el storytelling o la narrativa teniendo en cuenta que la autoría es un concepto cada vez más difuso, pero también esa retroalimentación entre palabra, imagen e interacción: los nuevos modos de narrar y crear no sólo condicionan la mirada, sino que el formato mismo de las plataformas usadas supedita la generación de dicho contenido.

Siguiendo de nuevo a Tranche (2016), podemos establecer una diferencia básica entre consumidores (de libros, periódicos, espectáculos) y prosumidores, que se relacionan con el contenido propuesto mediante búsquedas, likes y comentarios (interacciones que calificamos como pasivas) y comentarios, reseñas o textos alternativos (interacciones activas, en tanto que producen nuevos textos) pero también, crean su internet persona que puede ir desde una identidad virtual estrechamente vinculada a la "real" a un auténtico y propio metarrelato del yo. Otra cuestión interesante que se intentará abordar es hasta qué punto quien genera contenido más "canónico" en la red puede separar su identidad como autor de la persona: tenemos el caso más obvio de los influencers, ligados a un storytelling de marcada impronta mercantil, pero también hay que tener en cuenta la nueva generación de poesía nacida en y para Instagram, la narrativa de Wattpad o el cine ideado específicamente para Youtube. Ese acceso casi masivo a las redes con todas sus posibilidades permite que el sujeto sea el autor de su propia historia, creciendo exponencialmente bionarrativas de toda índole, pero también, permite que la narrativa no sea dominio de unos pocos con acceso a la publicación.

Las preguntas que esta nueva intertextualidad suscitan son difíciles de medir cuantitativamente por la propia naturaleza cambiante delas redes y los comportamientos a ellas vinculados. Debemos cuestionarnos, en primer lugar, en qué manera estos textos pueden pertenecer al canon, coartan o modifican el gusto del público o su percepción del mundo y en última instancia, si estos textos ejercen una influencia directa en la producción y edición de los artefactos culturales de índole más canónica. Igualmente, es necesario preguntarse cómo realizar un análisis sistemático de estos nuevos textos y, llegado el caso, llevar a cabo un cuestionamiento del concepto mismo de tradición. Sin embargo, ninguna de estas preguntas puede abordarse sin tener presente que a pesar de que en buena medida las redes sociales pueden ser consideradas un archivo personal o creativo, su organización vertical o cronológica, así como los algoritmos basados en la interacción que las gobiernan, hace que estos textos sean materia susceptible de ser olvidada (o de pasar desapercibida) por el propio flujo de información constante y novedosa.

\section{Hacia Un Nuevo Neobarroco}


Dossonlascaracterísticas que puedenidentificarse en esteestudiopreliminar sobrelos textos producidos online: la multiplicidad de mensajes y emisores (con las consecuentes transformaciones de los mismos) y el ansia del usuario por una experiencia total. A un nivel formal, podríamos hablar ya de una hipermodernidad bien diferenciada, aunque heredera de la ambigua postmodernidad; a un nivel estético; vincularíamos estos artefactos culturales al Neobarroco. En “El Barroco y su doble” (1990) Buci-Glucksman y Jarauta puntualizan que "más que de una vuelta al Barroco, habría que hablar de una vuelta del Barroco, entendido no ya como algo históricamente delimitado, sino como una forma de organización cultural con estrategias de representación propias" (11).

En la academia hispanohablante, vinculamos el estudio del Neobarroco a América Latina y se piensa inevitablemente en Sarduy, Carpentier o Perlongher, quien define el Neobarroco como una "desterritorialización furiosa" (Perlongher 1993: 48) que opera con sus propias reglas, contrapuestas a la lógica de la metrópoli y como resultado de procesos de mestizaje e innovación. Tomamos aquí la definición de Perlongher al tratarse de la más sintética y que tiene en cuenta la cuestión de clase: se trata de un arma deconstructiva, pero al servicio de una élite intelectual que busca una identidad americana esencial, creándose al mismo tiempo en el proceso de búsqueda. Se deconstruye el lenguaje y se analiza en micropartículas, cuestionando la relación entre significante y significado, tal y como proponen autores como Sarduy (1974) o Lezama Lima (1971) a su vez: del mismo modo que no se puede confiar en las palabras que nombran la realidad, también debe ponerse en cuarentena el modo de verla; y. si todo es cuestionable, también es, al mismo tiempo, polisémico.

Sin embargo, existe una abundante literatura sobre el Neobarroco como superestructura cultural global (o, al menos, Occidental), surgiendo una interesante contraposición entre la espectacularidad de la Contrarreforma y el último capitalismo:

\begin{abstract}
The neo-baroque combines the visual, the auditory, and the textual ways that parallel the dynamism of seventeenth-century baroque form, but the dynamism is expressed in the late twentieth and early twenty-first centuries in technologically and culturally different ways. Importantly, underlying the emergence of the neobaroque are transformed economic and social factors. (Ndalianis 2004: 5)
\end{abstract}

Podemos estudiar el Neobarroco como una suma de estilos y conceptos, pero no se trata de una mera adición, sino de sumar reinterpretando. Lo híbrido, no obstante incorpore lo precedente, es en sí mismo un nuevo estilo, una filosofía diversa. Y ese es el nexo epistemológico entre los estudios neobarrocos específicamente latinoamericanos y los globales: el hibridismo, dos o más elementos que, al imbricarse, resultan en un producto diverso. Sin embargo, hablando de hibridismo, lo importante no es lo que deja fuera, sino lo que incluye, y el Neobarroco, a nivel narrativo, engloba una serie de estrategias de inclusión en el discurso; en otras palabras, lo que era marginal, ahora 
tiene voz. No obstante, el proceso puede funcionar inversamente: utilizando una serie de mecanismos estéticos reconocibles, pueden hacerse pasar mensajes pro status quo, como se justificará más adelante.

Ndalianis (2004) señala la década de los cincuenta como el momento en el que los escritores latinoamericanos posaron su mirada en el siglo XVII: "the seventeenthcentury Baroque's obsessive concerns with illusionism and the questionable nature of reality was adapted to a new cultural context, becoming a formal strategy that might be used to context the "truth" of dominant ideologies, issues of identity, gender and "reality" itself" (273). Ndalianis se refiere efectivamente a un Barroco transhistórico, vinculando las transformaciones tecnológicas, industriales y económicas con la preferencia por experiencias sensoriales y la grandiosidad estética de lo que podrían llamarse "las ondas barrocas". Esta terminología la retomamos de la teoría de las ondas de Eugenio D'Ors (2013, fecha original de publicación 1944), para quien la humanidad se mueve cultural e incluso, políticamente entre eones clásicos y barrocos, ordenados y conservadores frente a otros caóticos y desestabilizadores. En esa misma línea, teóricos de lo postmoderno como Lyotard (1989) o Deleuze (1989) subrayan cómo la recuperación ventisecular de la etiqueta "barroco" va en consonancia con la tendencia postmoderna a leer el mundo como un corpus de textos polimórficos: en otras palabras, se usa el barroquismo no como etiqueta transhistórica sino, en la misma línea de D'Ors, como un rasgo de la modernidad.

Como precedente a esta propuesta, cabe destacar el estudio El Paisaje Virtual. El Cine de Hollywood y el Neobarroco Digital (2004) de López Silvestre, dedicado a la espectacularidad de efectos especiales y a la creación de mundos literalmente inexistentes. Estas creaciones serían producto de una sociedad occidental que cree vivir en un espejo, en un reflejo imperfecto con elementos reconocibles pero cercado por otros nuevos que dan a la realidad una apariencia irreconocible:

El régimen barroco está fascinado por la ilegibilidad de la realidad que representa. Imágenes deslumbrantes y desorientadoras -extasiantes- (...) múltiples puntos de vista, la asimetría, el trampantojo, las sombras... (...) El Barroco desprecia los intentos de reducir la multiplicidad de los espacios visuales a una única esencia coherente, y, frente al espejo plano y reflectante usado por la perspectiva analítica, se decanta por el espejo anamorfo, cóncavo o convexo, que distorsiona la imagen visual. (López Silvestre 2004: 29).

El concepto clave para este trabajo sería efectivamente el del espejo, que podría aplicarse al estudio de la pantalla, a quién mira, a quien es mirado y lo que refleja en última instancia. Por ejemplo, un elemento común a todos los creadores de contenido digital es la necesidad de crear y mantener un self-branding o automarca: desde los influencers a la nueva generación de poetas de Instagram, pasando por los autores de obras físicas que utilizan sus perfiles en redes sociales para dar notoriedad a su obra 
o, incluso completarla; en definitiva, todos los creadores de contenido cultivan una imagen que pretende reflejar un yo parcial e incompleto, fácilmente aprehensible y, en última instancia, vendible. Si bien la imagen personal juega un papel primordial en el contacto directo con el receptor (consumidor, espectador, lector), este también tiene lugar a través de nuevos subgéneros como el storytime. Ese tipo de narrativas personales que ficcionalizan en mayor o menor medida el yo autoral va en paralelo al auge de ciertos tipos de literatura tradicional en formato libro como los ensayos personales o las bionarrativas semificcionalizadas, muy populares en el mercado editorial estadounidense ${ }^{2}$.

Asimismo, y teniendo en cuenta los conceptos ya mencionados de Internet persona y webactors cabe plantearse si esa multiplicidad de mensajes significa una democratización del relato, un nuevo hibridismo de experiencias que hacen de lo narrativo algo más inclusivo. Ello conllevaría, si aceptamos la hipótesis de que el contenido virtual condiciona la producción y edición de libros, un interesante soporte para la creación literaria de mujeres y voces marginalizadas. Sin embargo, es asimismo posible plantearse si el emisor del mensaje "viral" o popular, y en última instancia, quien da el salto de lo virtual a la librería física mediante el apoyo de una editorial procede verdaderamente del margen o si se trata de una voz parte de un privilegio sancionado por el sistema.

Más allá de la posible perpetuación de jerarquías en el ámbito virtual parece claro que la interacción propia de las redes sociales y su uso masivo ofrecen una oportunidad sin precedentes por su carácter directo de combinar la interacción social con la creación individual, que a su vez se ve transformada sucesivamente en una especie de proceso de escritura colaborativa en diferido. Volviendo a la legitimación de ciertos productos a través de su salto al mundo editorial o al estudio académico, si bien es cierto que

2 En mayo de 2018, The New York Times publicó un artículo, escrito por Jia Tolentino, sentenciando el fin de la era de los ensayos personales. En él, se señalan los magazines feministas online y los blogs personales surgidos alrededor del año 2008 como iniciadores de una tendencia con repercusiones en el mercado editorial (piénsese en el caso de las múltiples reediciones de I love Dick de Chris Kraus (1997), obra de la que nació además una serie en el 2016). Menos de una década después, webs como xoJane o Jezebel ya no existen o no se dedican a la publicación de este tipo de historias. Este género, cultivado principalmente por mujeres, se construye alrededor de experiencias específicamente femeninas que suelen estar silenciadas (el aborto, la menstruación, los trastornos alimenticios o los problemas de mantener una relación heterosexual tóxica que no necesariamente se consideran maltrato). Tolentino apunta como causa del ocaso del ensayo personal no sólo el propio funcionamiento cambiante de las webs y redes sociales a nivel de visibilidad y monetización, sino también la apropiación del género por parte de autores de ideología de extrema derecha (en el caso estadounidense, simpatizantes de Trump) alrededor del año 2015. Este caso ejemplifica cómo fenómenos de gran relevancia e incluso impacto social son susceptibles no sólo de ser reutilizados con fines totalmente contrarios a su intención inicial, sino de ser olvidados. Es por ello que en este trabajo se defiende la necesidad de estudiar los textos producidos online como fotografías del momento, para lo cual es necesario un aparato crítico consciente de su propia naturaleza volátil. 
lo determina el algoritmo y la popularidad (pensemos en los poemarios de autores/ as surgidos en Instagram o en los volúmenes que recogen posts de blogs), a fin de cuentas, esa retroalimentación la dan los propios usuarios. Es decir, no solo la autoría se redefine a través de la (re)escritura colaborativa, sino que el concepto de industria editorial no es tan piramidal como antes, lo cual no significa necesariamente que exista una total democratización en la emisión del mensaje.

Siguiendo una aproximación teórica y basada en lo que los estudios neobarrocos nos dicen, podríamos dividir estos textos en dos niveles de lecturas: el meramente estético y el realmente subversivo, es decir, el que se sirve de las redes para configurar un contradiscurso. En primer lugar, podemos tener en cuenta la definición de Perlongher y cómo tomaba en consideración el hecho de que (casi) cualquier creación cultural pertenece a una élite. En segundo lugar, queda claro que las estructuras culturales continúan supeditadas tanto al ámbito académico y canónico como al editorial, de modo que no se puede hablar de una horizontalidad real: poder expresar y publicar un mensaje no conlleva necesariamente un éxito en la transmisión. Maravall (1981: 63), por su parte ya afirmaba que "El arte y la literatura del Barroco, que con frecuencia se declaran tan entusiastas de la libertad del artista o de la libertad en sus gustos del público, se hallan bajo la influencia o incluso mandato de los gobernantes (disciplina post Concilio de Trento) y esa característica del barroco "histórico" parece que se mantiene en este nuevo eón barroco". Las políticas de cada red social y los algoritmos juegan a favor del mantenimiento de un cierto orden en consonancia con la moral vigente, usando la palabra en sentido laxo.

¿Cuáles serían los elementos neobarrocos, en resumen? Podemos sintetizar el estudio de Calabrese (1987) en tres rasgos aplicables a estos nuevos textos: en primer lugar, ritmo y repetición, característica confirmada en el exceso de historias y de regularidad hasta la saturación (proliferación de tweets, serialidad en la creación y publicación) que persigue además evitar el aburrimiento mediante la saturación visual; en segundo lugar, excentricidad: si bien los márgenes presionan el orden, no llevan a tocarlo; es decir, la subversión es controlada por el propio mecanismo del sistema; finalmente, exceso (y antídoto) pues, a pesar de vivir inmersos en lo que Naomi Klein llama "doctrina del shock" (2008), conviven con ese tipo de textos y mensajes radicados en la sexualidad o el miedo otros basados en cambio en la perfección, o en el virtuosismo, incluso.

Es decir, lo neobarroco no es necesariamente sinónimo de subversión: se puede usar la excentricidad como una herramienta que perpetúe, precisamente, la centralidad. Así, es importante para este tipo de estudio con una perspectiva feminista tener en cuenta el concepto de marketplace feminism o feminismo de mercado (Zeisler 2016): 
Marketplace feminism is in many ways about just branding feminism as an identity that everyone can and should consume. That's not a bad thing in theory, but in practice it tends to involve highlighting only the most appealing features of a multifaceted set of movements. It kicks the least sensational and most complex issues under a rug and assures them that we'll get back to them once everybody's on board. (74)

En el imaginario colectivo surgido a raíz de la generalización de las redes sociales, parece plausible hablar intuitivamente de una explosión feminista y acercarse al análisis de estos nuevos textos con cierto optimismo al constatar las oportunidades a priori igualitarias para la creación y difusión de mensajes. No obstante, por el propio mecanismo de las redes, no puede considerarse que estemos ante una verdadera subversión, sino que más bien el reclamo de un presunto igualitarismo sirve para generar interacción y respuestas positivas sin necesariamente cuestionar el funcionamiento mismo del sistema. Efectivamente, valorar la experiencia personal frente a lo normativo resulta fundamental para un análisis feminista que catalogue y haga crítica de los artefactos culturales producidos por mujeres, renunciando a una óptica canónica tradicionalista. No obstante, tal y como se explicará en el próximo apartado, resulta imperativo un aparato teórico que tenga en cuenta las propias fallas del sistema, a saber: la sobreabundancia de productos y textos que no van más allá de una gratificación instantánea basada en el gusto por la novedad frente a la existencia de un potencial corpus de textos que realmente constituyan un contradiscurso narrativo que complete la noción de universalidad literaria y cuestione la identificación misma de masculino con universal.

\section{El CONCEPTO de THEATRUM MUNDI APLICAdO A LA HiperMOdERNIDAd}

Más allá del análisis crítico de la estética o la ficción, autores como Lipovetsky hablan de una cultura "antinómica" (2015: 81) en la que una nueva lógica artística basada en la novedad y el cambio constantes emerge, lo cual esencialmente constituye un nuevo modelo que libera la creación de tradición y colectividad para considerar cada artefacto artístico y literario como expresión individual, voluntariamente al margen de lo canónico. En Les temps hypermodernes (publicado originalmente en 2004) lleva su análisis más allá del campo de la producción cultural y vincula la hipermodernidad con el hipercapitalismo y las actitudes sociales, con consecuencias en conductas y decisiones condicionadas cotidianas como vestirse (recuérdese la teoría de Calabrese), alimentarse o incluso morir (2014: 57), consecuencias que también podríamos vincular a ese "pasivismo" que comentamos anteriormente. Trabajos recientes como el anteriormente citado de Tranche (2019) analizan los medios de comunicación actuales, el impacto de la imagen y la sobreexposición a un flujo incesante de noticias e imágenes, al que denomina panóptico reticular (132), como si fueran una máscara sobre 
la realidad: es decir, un filtro que esconde otras narrativas $\mathrm{y}$, al mismo tiempo, una barrera para comprenderlas realmente a pesar del acceso perpetuo a la información. Este filtro podría ser nada menos que la pantalla.

Lipovetsky considera las pantallas como un fenómeno moderno y su proliferación, exclusivamenteposmoderna: vivimosenunmundodeimágenesperpetuas, instantáneas y fragmentarias, borrando la oposición entre distancia y cercanía, erosionando cualquier narrativa continua en lo que él llama "la era de la tercera pantalla" (2013): el cine (colectivo), la televisión (colectiva en el ámbito del hogar y, posteriormente, individual) y el ordenador (cuya situación sería asimilable a la de la televisión). Sin embargo, con la extensión del uso del teléfono inteligente, nos encontramos no sólo ante una multiplicación de pantallas individuales, sino también ante una proliferación de agentes y creadores. Surge entonces una pregunta obvia: ¿esto realmente implica que tenemos una proliferación de discursos o solo uno reticular? Resulta entonces imperativo, a la hora de analizar los discursos virtuales, tener en cuenta los factores que hacen que un discurso perviva, tenga éxito o se pierda en el mencionado eje reticular: en otras palabras, el gusto por la novedad no implica la creación o existencia de nuevos discursos, sino que se observa una tendencia en ciertas redes (Instagram, Snapchat, TikTok o Twitter) a repetir la misma tendencia, perpetuando ideas, textos y, en última instancia, comportamientos.

Para Lipovetsky, desde la era del pluriequipment (2013) de los hogares (un televisor para cada miembro de la familia, por ejemplo) los comportamientos se están homogeneizando e individualizando, en una especie de doble proceso aparentemente contradictorio. En esa misma línea, también Marina Garcés (2018) analizó la creación o nacimiento de una cultura del hiperconsumismo ligada al presente y la novedad como valores máximos, formas en definitiva de escapar de la miseria cotidiana: se trata de la condición póstuma, una "quiebra del presente eterno y la puesta en marcha de un no-tiempo" (Garcés 2018:23) que conlleva la negación del futuro y una consecuente "catástrofe del tiempo" (24).

Para concluir este apartado, podemos cerrar el círculo uniendo el extremo hipermoderno al neobarroco teniendo en cuenta la visión de Lambert (2004) al respecto, quien considera que "no hay nada particularmente moderno en lo posmoderno, pero que podría entenderse, en cierto sentido, como un "retorno del barroco "(2004: xxiv). Por tanto, el Neobarroco puede considerarse un marco teórico que abarca también la producción de transmisores y receptores de información y cultura a través de los mecanismos que brindan las redes sociales. De ese modo, podemos encuadrar futuros estudios sobre autorías marginalizadas de un modo sistemático, alejado de lo anecdótico de un fenómeno "viral" puntual, y en última instancia, estudiar los "contradiscursos" provenientes de voces periféricas al canon hegemónico. 


\section{Abriendo vías hacia Un futuro análisis: algunos textos (O post TEXTOS) SUSCEPTIBLES DE CATALOGACIÓN.}

Una de las dificultades intrínsecas a este tipo de estudio es la preeminencia del pathos y el ethos sobre el logos en los textos susceptibles de análisis: en otras palabras, las historias y el lenguaje llamativo (pathos), así como la marca personal e imagen presentada online (ethos) son determinantes para la configuración de un discurso con éxito online, entendiendo éxito como número de veces que se comparte o se reescribe el texto inicial. Ello no implica necesariamente que el artefacto discursivo exitoso posea una calidad, entendida ésta en sentido laxo, que pueda trascender la fama efímera. No obstante, y a pesar de la prevalencia de ciertos generadores de contenido, existen narrativas marginales con éxito que vendrían a demostrar que las redes sociales, con sus limitaciones, pueden ser utilizadas como mecanismos que incorporen al centro o al menos, a la periferia de lo aceptable, discursos y voces tradicional y plenamente periféricos.

Un campo interesante para explorar sería el de la "tuiteratura", con sus correspondientes subgéneros (twiller -tweet + thriller- o twovel -tweet + novel-), manifestaciones literarias nacidas adecuadas a la propia plataforma y que perviven a día de hoy a pesar de los pronósticos de algunos críticos. (Torres 2014: 209). Los ciento cuarenta caracteres por tweet, lejos de servir de límite, son un estímulo creativo, unido al hecho de que se contribuye a la creación de un nuevo género $(\mathrm{o}$, si se quiere, subgénero del relato corto) en tiempo real y con características propias: el suspense, especialmente en el primer tweet, sería esencial para captar la atención y estimular la interacción. Cabe decir que, frente a los 330 millones de usuarios de Twitter, las redes en las que prima lo visual son mucho más utilizadas: baste comparar esa cantidad con el billón de usuarios de Instagram. Por su combinación de fotografía, vídeo y texto, Instagram podría servir asimismo como una red susceptible de análisis en el que se tenga también en cuenta la narración oral y, por su propia naturaleza, cross-media. Intuitivamente, un campo de estudio que se nos abre es el de las autobiografías a través del contenido generado en redes sociales.

En esa misma línea, podría llevarse a cabo un estudio generalizado de la bionarrativa de no ficción, es decir, de los relatos propios que ofrecen una alternativa al de la experiencia compartida y oficial: lo que es frente a lo que se dice que es. Se podrían considerar como un corpus de contradiscursos, seleccionando y confrontando aquellas narrativas que nazcan y perpetúen la normatividad frente a aquellas que la rechazan y, en cierta medida, la redefinen. Serían susceptibles de este análisis los textos orales en formato de vídeo breve, los pies de foto de las redes sociales o publicaciones de blogs que, en conjunto, buscan explicar al sujeto. Se podrían aplicar estándares de 
crítica literaria y análisis del discurso a estos textos con características propias que podríamos resumir en brevedad e inmediatez, no sin olvidar la interacción y las sucesivas transformaciones generadas en el proceso de recepción. Se trata de casos para cuyo análisis sería necesario equiparse con nuevas herramientas que tengan en cuenta que la materia narrable son las propias autoras, pero no ellas en sí mismas (recuérdese la diferencia entre persona, webactor e Internet persona), sino una nueva narradora homodiegética virtual.

Desde una perspectiva meramente visual, las autofotos o selfies se están considerando desde un análisis feminista un modo de devolver la agencia de la mirada a quienes siempre fueron miradas (Tiidenberg y Gómez Cruz 2015): en ese sentido, el mundo del arte, a diferencia de lo que sucede con la crítica literaria, es más proclive a experimentar con el estudio de nuevas obras transmedia e incluso de autoría difusa. Un ejemplo relevante para el presente trabajo de este tipo de narrativa sería la obra Skeens (skin + screen, piel y pantalla) de Elisa Cuesta (2019) que a partir de sus datos privados generados en los últimos diez años en Facebook propone un ejercicio de decodificación y posterior materialización de su información en forma de tejidos, tapices e instalaciones. Si bien la palabra es esencial en el espacio museístico que se designe para su exposición, dado que sin ella la obra carecería de dirección autónoma, es lo visual lo que prima en la sala. Lo interesante es que esas obras nacen del código proporcionado por la red social como datos medibles que, salvo por las interacciones pasivas (clicks, me gustas o acciones de compartir sin comentario) nacen sustancialmente de la palabra. La artista clasificó sus datos en tres categorías: autoedición o acciones voluntarias que contribuyen al diseño del propio perfil; interacción, aquellas correspondientes al intercambio de información con otros relatos; registrales, acciones propias de la plataforma, realizadas al margen de la usuaria, con fines analíticos (y, en última instancia, comerciales). Es decir, la palabra (y no sólo por la ingeniería propia de la red, basada en el lenguaje informático) convive en igualdad de condiciones con acción, reacción e imagen.

Otro ejemplo de literatura colaborativa que culmina en lo visual y, finalmente, en el espacio museístico, sería la obra de Caroline Sinders Feminist Data Set (2017-2019): se trata de un experimento transmedia en toda regla que inicia con talleres y conferencias presenciales $^{3}$ que recopilan datos sobre la imagen de la mujer y se cruzan con otros sobre feminismo. Dichos datos servirán de alimento para entrenar una inteligencia artificial a operar con perspectiva feminista, que dará como resultado final una serie de pósters con aforismos o sentencias generadas por ella. La obra en sí plantea un dilema sobre la autoría difusa: en última instancia, ¿quién es la autora del producto

3 En Asturias tuvo lugar en 2019 al amparo de la exposición Deus Ex Machina de la Universidad Laboral de Gijón, por lo que la propia obra permuta a través de categorías de tiempo y espacio. 
final: Sinders, las participantes o la IA? Y más allá de dicho producto final, ¿cuál sería el verdadero artefacto cultural: los pósters, el código diseñado para la IA o el proceso de recolección de datos en las actividades presenciales?

En definitiva, cabría preguntarse si son estas nuevas formas de narrativa, dado que se entrelazan sin aparente jerarquía palabra, imagen e hipervínculo, o si, tal y como se hipotetizó al inicio de este trabajo, son productos efímeros dado el constante flujo de textos e imágenes. En cualquier caso para abordar un posible estudio sistemático de estos textos, aun a nivel sincrónico, es necesario distinguir entre el storytelling tradicional del nuevo storyliving (Orihuela 1997), etiqueta nacida para definir la interacción por parte de usuarios en los primeros motores narrativos (Story Space, Story Vision y Movie Magic Screening), y que bien podría aplicarse ahora al análisis de los continuos ensayos personales creados específicamente para las redes y con un formato condicionado por el soporte.

\section{CONCLUSIONES: DIRECCIONES HACIA FUTURAS INVESTIGACIONES.}

El objetivo de este trabajo ha sido presentar una contextualización genérica de las nuevas formas de literatura online, estructurada al amparo de las teorías neobarrocas e hipermodernistas que tienen en cuenta la multiplicidad de textos y narrativas, su naturaleza híbrida y, además, el nuevo concepto de autoría difusa gracias a los mecanismos colaborativos. Más que responder a cuestiones concretas, este estudio preliminar se propone nuevas preguntas: ¿Son estos ejemplos (bionarrativas, microrrelatos (orales o escritos), storytelling cross media...) plenamente nuevas formas de narrativa, dado que conviven en igualdad de condiciones palabra, imagen e hipervínculo? Y si nos centramos en las obras que hacen uso exclusivo de la palabra ¿estamos ante una postnarrativa, o se trata aún de una categoría inestable? O, siguiendo a Lipovetsky, si estas obras rechazan la tradición y se basan en la novedad, ¿merece la pena considerarlas materia susceptible de estudio académico, si precisamente nacen con clara intención de permanecer al margen?

Dado su papel en la cultura contemporánea, si bien resulta problemático el estudio de fenómenos singulares por su naturaleza efímera, parece cuanto menos necesario, sin embargo, realizar una fotografía del momento: material de análisis serían los textos creados en plataformas tales como Wattpad o Wakelet, dedicadas específicamente a la narración más tradicional, si se quiere (aunque no necesariamente lineal) y los experimentos más arriesgados surgidos en redes como Twitter (la llamada tuiteratura) o Pinterest, que no fueron ideadas para la narración. Abren la puerta no sólo a la multiplicación de textos, sino a la autoría múltiple y a la creación de novelas en la acepción más clásica del término. Este tipo de narrativas, además, se desvinculan parcialmente del yo y la (meta)narración autobiográfica propia de las redes sociales, 
sino que dan el paso pleno hacia la ficción. Asimismo, en este estudio preliminar se han ofrecido algunos ejemplos vinculados al mundo del arte que ilustran cómo las mujeres creadoras reaccionan a este específico momento histórico, utilizando los elementos virtuales no ya como soporte, sino como materia narrable, reocupando los espacios museísticos como puntos de narración autobiográfica e incluso activista En definitiva, surge la necesidad de realizar estudios que expandan la definición de literatura y tengan en cuenta el uso inextricable de palabra y materia.

Por último, tal y como se ha intentado ilustrar a lo largo de este trabajo, la (relativa) democratización tecnológica abre la puerta a un análisis con perspectiva feminista y transversal, dado que las trabas tradicionalmente impuestas al acceso a la creación literaria a ciertos grupos marginalizados, si bien no se pierden absolutamente, sí se difuminan. Asimismo, la proliferación de creadoras y textos fácilmente accesibles sería también materia susceptible de estudio, al cambiar de paradigma sin literary foremothers (retomando el concepto de Eagleton 2014) a otro con múltiples figuras referenciales; no obstante, ese análisis debería tener en cuenta el tipo de referencia ejercida y sobre qué nicho de población, así como la posibilidad que abre a la intertextualidad entre escritoras. En ese sentido, las redes sociales cuestionan el papel de la editoría y la crítica, permitiendo que ciertos discursos y textos salgan a la luz sin filtro o cura y que voces tradicionalmente marginadas puedan tener su propio espacio, por exiguo que este resulte. En definitiva, ante este nuevo paradigma dominado por la pantalla, parece oportuno preguntarse qué significa específicamente para las mujeres construirse desde el espejo y a través de él, en qué medida eso condiciona su libertad expresiva y si, a fin de cuentas, el nuevo paradigma es una reproducción del preexistente o si constituye una oportunidad de apertura del canon que realmente defina el concepto de universalidad.

\section{REFERENCIAS BIBLIOGRÁFICAS}

Ardener, S., "Ardener's "Muted Groups": The genesis of an idea and its praxis", Women and Language, 28.2 (2005), pp. 50-72.

Calabrese, O., La Era Neobarroca, Madrid, Cátedra, 1987.

Deleuze, G., El pliegue. Leibniz y el barroco, Barcelona, Paidós, 1989.

D’Ors, E., Lo Barroco, Madrid, Tecnos/Anaya, 2013 (primera edición: 1944)

Eagleton, M., Feminist literary criticism, Londres, Routledge, 2014.

Garcés, M., Nueva ilustración radical, Barcelona, Anagrama, 2017.

Jarauta, F., y Buci-Glucksmann C., "El barroco y su doble”, Cuadernos del círculo, 2 (1993): pp. 11-12.

Klein, N., La doctrina del shock: el auge del capitalismo del desastre, Barcelona, Paidós, 2007. 
Kraus, C., I love Dick, París, Flammarion, 2016.

Lambert, G,. On the (New) Baroque, Aurora, The Dacies Group Publishers, 2008.

Lezama Lima, J., Las Eras Imaginarias, Madrid, Fundamentos, 1971.

Lipovetsky, G, Los Tiempos Hipermodernos. Madrid, Anagrama, 2014, (primera edición: 2004).

Lipovetsky, Gilles, "La pantalla global”. Cátedra Alfonso Reyes. Youtube. 9-10-2013 https://n9.cl/7ql2

López Silvestre, F., El Paisaje Virtual. El Cine de Hollywood y el Neobarroco Digital, Madrid, Biblioteca Nueva, 2004.

Lyotard, J.F, La condición postmoderna, Madrid, Cátedra.

Maravall, J.A., La cultura del Barroco. Análisis de una estructura histórica, Barcelona, Ariel, 1981.

Ndalianis, A., Neo-Baroque Aesthetics and Contemporary Entertainment, Cambridge, Massachusetts, The MIT Press, 2004.

Orihuela, J.L., "Narraciones interactivas: el futuro no lineal de los relatos en la era digital." Palabra clave, 2 (1997), pp. 37-46

Perlongher, N., "Introducción a la Poesía Cubana y Rioplatense", Revista Chilena de Literatura, 41 (1993), pp. 47-57.

Sarduy, S., Barroco, Buenos Aires, Sudamericana, 1974.

Scolari, C., "Narrativas transmedia: nuevas formas de comunicar en la era digital". Anuario AC/E de cultura digital, 1 (2014): pp. 71-81.

Tiidenberg, K. y Gómez Cruz, E., "Selfies, image and the re-making of the body", Body \& society, 21.4 (2015), pp. 77-102.

Tolentino, J., "The personal essay boom is over", The New York Times, Internet, 18-05-17 shorturl.at/jwCVY

Torres Begines, C., “Novelas en Twitter: el fenómeno de la narrativa en 140 caracteres.” Espéculo Revista de Estudios Literarios, 54 (2014), pp. 208-220.

Tranche, R. R. (2019). La Máscara sobre la Realidad. La Información en la Era Digital. Madrid: Alianza Editorial, 2019.

Zeisler, A., We were feminists once: From riot grrrl to CoverGirl, the buying and selling of a political movement, Public Affairs, 2016. 